\title{
Histological subtype and smoking status, but not gender, are associated with epidermal growth factor receptor mutations in non-small-cell lung cancer
}

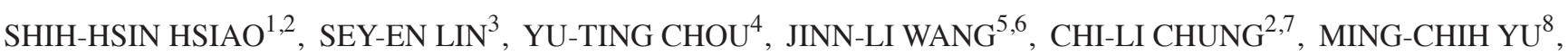 \\ CHIA-LANG FANG ${ }^{9}$, HSIN-LUN LEE ${ }^{10}$, LING-LING CHIANG ${ }^{7}$, H. EUGENE LIU ${ }^{6,11^{*}}$ and CHENG-WEN WU ${ }^{1,4 *}$ \\ ${ }^{1}$ Molecular Medicine Program, School of Life Sciences, National Yang-Ming University; ${ }^{2}$ Division of Pulmonary Medicine, \\ Department of Internal Medicine; ${ }^{3}$ Department of Pathology, Taipei Medical University Hospital; \\ ${ }^{4}$ Institute of Biomedical Science, Academia Sinica; ${ }^{5}$ Department of Pediatrics, Department of Medicine, Wan Fang Hospital; \\ ${ }^{6}$ Graduate Institute of Clinical Medicine; ${ }^{7}$ School of Respiratory Therapy, College of Medicine, Taipei Medical University; \\ ${ }^{8}$ Division of Pulmonary Medicine, Department of Medicine, Wan Fang Hospital; ${ }^{9}$ Department of Pathology, \\ College of Medicine; ${ }^{10}$ Department of Radiation Oncology; ${ }^{11}$ Division of Hematology and Oncology, \\ Department of Medicine, Wan Fang Hospital, Taipei Medical University, Taipei, Taiwan, R.O.C.
}

Received February 16, 2013; Accepted August 15, 2013

DOI: $10.3892 / \operatorname{mco} .2013 .232$

\begin{abstract}
Mutations in epidermal growth factor receptor $(E G F R)$ commonly occur in non-small-cell lung cancer (NSCLC) patients characterized by female gender, never-smoker status and adenocarcinoma histology. The aim of this study was to determine whether gender is a confounding factor for $E G F R$ mutations in NSCLC. To elucidate the confounding effect, Pearson's $\chi^{2}$ test and logistic regression models were used to correlate these characteristics with $E G F R$ mutations in 426 NSCLC patients treated at our institutes. Of those 426 NSCLC patients, $47 \%$ were females, $57 \%$ were non-smokers and $84 \%$ had adenocarcinomas. The multivariate logistic regression analysis demonstrated that never-smoker status [odds ratio $(\mathrm{OR})=3.49,95 \%$ confidence interval (CI): 1.99-6.13; $\mathrm{P}<0.001)]$ and adenocarcinoma $(\mathrm{OR}=9.43,95 \%$ CI 3.62-24.56; $\mathrm{P}<0.001)$ were associated with $E G F R$ mutations; however, gender was not $(\mathrm{OR}=1.25,95 \% \mathrm{CI}$ : 0.73-2.15; $\mathrm{P}=0.416)$. Furthermore, gender was not associated with $E G F R$ mutation subtypes $(\mathrm{OR}=1.19,95 \% \mathrm{CI}$ : 0.56-2.50; $\mathrm{P}=0.650)$. The frequency of EGFR mutations among females and males was not different in non-smokers (64.8 vs. $55.8 \%, \mathrm{P}=0.204)$
\end{abstract}

Correspondence to: Dr H. Eugene Liu, Division of Hematology and Oncology, Department of Internal Medicine, Wan Fang Hospital, Taipei Medical University, 111 Hsin-Long Road, Section 3, Wenshan District, Taipei 110, Taiwan, R.O.C.

E-mail: liuxx086@tmu.edu.tw

*Contributed equally

Key words: gender, a confounding factor, epidermal growth factor receptor mutations, non-small-cell lung cancer or ever-smokers (27.8 vs. $24.2 \%, \mathrm{P}=0.775)$. Therefore, if the assessment for EGFR mutation status was limited to non-smoking females with adenocarcinoma, up to $40 \%$ of the patients harboring EGFR mutations would be precluded from the benefit of EGFR inhibitor therapy. Our results indicated that gender is a confounding factor for EGFR mutations in NSCLC and suggested that gender may not be associated with tumorigenesis in NSCLC-harboring EGFR mutations.

\section{Introduction}

Smoking, the major risk factor for lung cancer, is associated with all major histological subtypes, particularly small-cell and squamous cell lung carcinoma. By contrast, adenocarcinoma is the predominant subtype of lung cancer encountered in never-smokers (1-3). Global statistics estimated that $15 \%$ of lung cancer cases in males and 53\% in females are not associated with smoking. Furthermore, among the East Asian populations, $11-23 \%$ of male and $61-90 \%$ of female lung cancer patients are never-smokers (1-7).

In lung cancer patients from Asia-Pacific countries, mutations in the epidermal growth factor receptor (EGFR) are the most common genetic aberrations (8-12) and are significantly associated with a good response to treatment with EGFR tyrosine-kinase inhibitors (TKIs). First-line EGFR-TKI therapy with gefitinib or erlotinib (13-17) in patients with lung adenocarcinoma harboring EGFR mutations may yield a response rate of $\sim 70 \%$ and achieve a longer progression-free survival (PFS) $(8-11,17)$. EGFR mutations are commonly associated with female gender, adenocarcinoma histology, never-smoker status and Asian ethnicity $(9,13,14,18-21)$. Therefore, these characteristics have been integrated into clinical practice to guide treatment selection for patients with advanced lung cancer (13,14,22-24).

However, these EGFR mutation-associated clinicopathological characteristics are probably mutually interactive. For 
Table I. Association of clinicopathological characteristics of NSCLC patients with EGFR mutations.

\begin{tabular}{|c|c|c|c|c|}
\hline \multirow[b]{2}{*}{ Characteristics } & \multirow[b]{2}{*}{$\begin{array}{c}\text { Total } \\
(\mathrm{n}=426)\end{array}$} & \multicolumn{2}{|c|}{$E G F R$ mutations } & \multirow[b]{2}{*}{ P-value } \\
\hline & & $\begin{array}{l}\text { Present } \\
(\mathrm{n}=197)\end{array}$ & $\begin{array}{l}\text { Absent } \\
(\mathrm{n}=229)\end{array}$ & \\
\hline Age (years) & & & & 0.094 \\
\hline$\geq 60$ & $294(69)$ & $128(44)$ & $166(56)$ & \\
\hline$<60$ & $132(31)$ & $69(52)$ & $63(48)$ & \\
\hline Gender & & & & $<0.001$ \\
\hline Male & $226(53)$ & $74(33)$ & $152(67)$ & \\
\hline Female & $200(47)$ & $123(62)$ & 77 (39) & \\
\hline Smoking status & & & & $<0.001$ \\
\hline Smokers & $183(43)$ & $45(25)$ & $138(75)$ & \\
\hline Non-smokers & $243(57)$ & $152(63)$ & $91(37)$ & \\
\hline Histology & & & & $<0.001$ \\
\hline Adenocarcinoma & $359(84)$ & $192(53)$ & $167(47)$ & \\
\hline Non-adenocarcinoma & $67(16)$ & $5(7)$ & $62(93)$ & \\
\hline Stage & & & & 0.842 \\
\hline Local and advanced & $352(83)$ & $162(46)$ & $190(54)$ & \\
\hline Early & 74 (17) & $35(47)$ & $39(53)$ & \\
\hline
\end{tabular}

${ }^{a}$ Includes squamous cell carcinoma, adenosquamous carcinoma and large-cell carcinoma. NSCLC, non-small cell carcinoma; EGFR, epidermal growth factor receptor. Parenthetical data represent percentage values.

example, in Asian countries, the majority of female lung cancer patients are never-smokers and have tumors of the adenocarcinoma subtype, which makes it difficult to determine whether gender, smoking history or histological subtype is the decisive factor for $E G F R$ mutations. The identification of the decisive factor associated with EGFR mutations is essential for designing preventive strategies and therapeutic interventions and for the elucidation of the processes underlying tumorigenesis in lung cancer. Therefore, it is critical to determine whether these well-established clinicopathological characteristics associated with EGFR mutations in NSCLC patients are confounded with each other. Thus, we retrospectively analyzed data retrieved from our institutes to elucidate the association between EGFR mutations and clinicopathological characteristics.

\section{Patients and methods}

Patients and variables. We retrospectively analyzed the clinicopathological characteristics of NSCLC patients who had adequate tumor tissue for EGFR mutation analyses of exons 18-21, between January, 2006 and August, 2011. Variables including age, gender, histological subtype, smoking history, disease stage and the presence and location of EGFR mutations were collected and analyzed. A patient was classified as a non-smoker if he/she had never smoked or had smoked $<100$ cigarettes during their lifetime. By contrast, an ever-smoker was defined as one who had smoked >100 cigarettes over their lifetime. For histological classification, we grouped the histology as adenocarcinoma and non-adenocarcinoma. Among the non-adenocarcinomas, 32 were squamous cell carcinomas, 28 were NSCLCs not otherwise specified,
4 were adenosquamous carcinomas and 1 was a large-cell carcinoma.

This study was approved by the Joint Institutional Review Board of Taipei Medical University (Taipei, Taiwan). Informed patient consent was obtained.

EGFR mutation analysis. EGFR mutations were determined using either direct sequencing or other previously described methods $(25,26)$.

Statistical analysis. The association between EGFR mutation status and age, gender, histological subtype, smoking status and disease stage were evaluated using the Pearson's $\chi^{2}$ test or the Fisher's exact test when appropriate. Univariate (unadjusted) and multivariate logistic regression models (ULR and MLR, respectively) were used to delineate the effects of these established clinicopathological characteristics on EGFR mutations and the results were described as odds ratio (OR) with a $95 \%$ confidence interval (CI) and P-value. Furthermore, patients were stratified by smoking status to elucidate the association between EGFR mutations and the variables mentioned above. $\mathrm{P}<0.05$ was considered to indicate a statistically significant difference. Data analyses were conducted using SPSS software version 15.0 (SPSS Inc., Chicago, IL, USA).

\section{Results}

Clinical characteristics and EGFR mutation status. We analyzed the clinical characteristics and EGFR mutation status of 426 NSCLC patients (Table I). Of the 426 patients, 359 (84\%) had adenocarcinoma, 67 (16\%) had non-adenocarcinoma 
Table II. Logistic regression analysis of clinicopathological characteristics as predictors of the presence of EGFR mutations.

\begin{tabular}{lcccccc}
\hline & \multicolumn{3}{c}{ Univariate analysis } & & \multicolumn{2}{c}{ Multivariable analysis } \\
\cline { 2 - 5 } Predictor & OR & $95 \%$ CI & P-value & & OR & $95 \%$ CI \\
\hline Age ( $\geq 60$ years) & 0.70 & $0.47-1.06$ & 0.095 & 0.84 & $0.53-1.33$ \\
Gender (female) & 3.28 & $2.20-4.89$ & $<0.001$ & 1.25 & $0.73-2.15$ \\
Smoking (non-smokers) & 5.12 & $3.35-7.84$ & $<0.001$ & 3.49 & $1.99-6.13$ & 0.452 \\
Histology (adenocarcinoma) & 14.26 & $5.60-36.30$ & $<0.001$ & 9.43 & $3.62-24.56$ \\
Stage (local and advanced) & 0.95 & $0.57-1.57$ & 0.842 & 0.84 & $0.47-1.49$ \\
\hline
\end{tabular}

EGFR, epidermal growth factor receptor; OR, odds ratio; CI, confidence interval. Valid n=426.

Table III. Association of clinicopathological characteristics with EGFR L858R vs. del 19.

\begin{tabular}{|c|c|c|c|c|c|c|c|}
\hline \multirow[b]{2}{*}{ Characteristics } & \multirow[b]{2}{*}{$\begin{array}{c}\text { Total } \\
(n=185)\end{array}$} & \multicolumn{2}{|c|}{$\begin{array}{c}E G F R \\
\text { mutation type }\end{array}$} & \multirow{2}{*}{$\begin{array}{l}\begin{array}{c}\text { Univariate } \\
\text { analysis }\end{array} \\
\text { P-value }\end{array}$} & \multicolumn{3}{|c|}{$\begin{array}{l}\text { Multivariate } \\
\text { analysis }^{\mathrm{a}}\end{array}$} \\
\hline & & $\begin{array}{l}\text { del } 19 \\
(n=82)\end{array}$ & $\begin{array}{l}\text { L858R } \\
(n=103)\end{array}$ & & OR & $95 \% \mathrm{CI}$ & P-value \\
\hline Age (years) & & & & 0.143 & & & \\
\hline$\geq 60$ & $119(64)$ & $48(40)$ & $71(60)$ & & 1.52 & $0.82-2.80$ & 0.184 \\
\hline$<60$ & $66(36)$ & $34(52)$ & $32(48)$ & & Reference & & \\
\hline Gender & & & & 0.642 & & & \\
\hline Male & $71(38)$ & $33(46)$ & $38(54)$ & & Reference & & \\
\hline Female & $114(62)$ & $49(43)$ & $65(57)$ & & 1.19 & $0.56-2.50$ & 0.650 \\
\hline Smoking status & & & & 0.863 & & & \\
\hline Smokers & $44(24)$ & $20(45)$ & $24(55)$ & & Reference & & \\
\hline Non-smokers & $141(76)$ & $62(44)$ & $79(56)$ & & 0.89 & $0.37-2.11$ & 0.789 \\
\hline Histology & & & & $0.172^{\mathrm{b}}$ & & & \\
\hline Adenocarcinoma & $180(97)$ & $78(43)$ & $102(57)$ & & 4.89 & $0.52-45.98$ & 0.165 \\
\hline Non-adenocarcinoma $^{c}$ & $5(3)$ & $4(80)$ & $1(20)$ & & Reference & & \\
\hline Stage & & & & 0.918 & & & \\
\hline Local and advanced & $154(83)$ & $68(44)$ & $86(56)$ & & 1.13 & $0.51-2.49$ & 0.760 \\
\hline Early & 31 (17) & $14(45)$ & $17(55)$ & & Reference & & \\
\hline
\end{tabular}

${ }^{\mathrm{a}}$ Valid $\mathrm{n}=185 .{ }^{\mathrm{b}}$ Fisher's exact test. ${ }^{\mathrm{c} I n c l u d e s}$ squamous cell carcinoma, adenosquamous carcinoma and large-cell carcinoma. EGFR, epidermal growth factor receptor; OR, odds ratio; CI, confidence interval. Parenthetical data represent percentage values.

NSCLC, $47 \%$ were females, $57 \%$ were non-smokers and $43 \%$ were ever-smokers. Of the 226 male patients, $73 \%$ were ever-smokers, whereas only $8 \%$ of the 200 female patients were ever-smokers. In total, 197 (47\%) of the 426 patients were found to harbor EGFR mutations. Using the $\chi^{2}$ test, our results demonstrated that female gender, adenocarcinoma and non-smoking status were significantly associated with EGFR mutations in NSCLC (Table I). In detail, female patients had a higher EGFR mutation rate compared to males (62 vs. $33 \%, \mathrm{P}<0.001)$ and non-smokers had a higher EGFR mutation rate compared to ever-smokers (63 vs. $25 \%, \mathrm{P}<0.001)$. Patients with adenocarcinoma were more likely to harbor EGFR mutations compared to those with non-adenocarcinoma NSCLC (53 vs. 7\%, P<0.001). In conclusion, our data were consistent with those reported by previous studies $(9,13,14,18-21)$, demonstrating that gender, histological subtype and smoking are associated with EGFR mutations in a ULR analysis (Table II).

To eliminate the possible confounding effect, MLR analysis was used to evaluate the complex associations between these factors in the presence of EGFR mutations in NSCLC patients and demonstrated that gender was not an independent factor statistically associated with the presence of EGFR mutations in NSCLC patients $(\mathrm{OR}=1.25, \mathrm{P}=0.416)$ (Table II). However, adenocarcinoma and never-smoker status were independently associated with the presence of EGFR mutations (OR=9.43, $\mathrm{P}<0.001$ and $\mathrm{OR}=3.49, \mathrm{P}<0.001$, respectively).

EGFR mutation subtypes. In our study, 185 (93.9\%) of the 197 EGFR mutations were either a deletion in exon 19 (del 19) $(41.6 \%)$ or a single amino acid substitution in exon 21 
Table IV. Association of clinicopathological characteristics with the presence of EGFR mutations in patients classified by smoking status.

\begin{tabular}{|c|c|c|c|c|c|c|}
\hline \multirow[b]{2}{*}{ Characteristics } & \multicolumn{3}{|c|}{ Smokers $(n=183)$} & \multicolumn{3}{|c|}{ Non-smokers $(n=243)$} \\
\hline & $\begin{array}{l}E G F R^{+} \\
(\mathrm{n}=45)\end{array}$ & $\begin{array}{c}E G F R^{-} \\
(\mathrm{n}=138)\end{array}$ & P-value & $\begin{array}{c}E G F R^{+} \\
(\mathrm{n}=152)\end{array}$ & $\begin{array}{l}E G F R^{-} \\
(\mathrm{n}=91)\end{array}$ & $\mathrm{P}$-value \\
\hline Age (years) & & & 0.337 & & & 0.611 \\
\hline$\geq 60$ & $31(23)$ & $105(77)$ & & $97(61)$ & $61(39)$ & \\
\hline$<60$ & $14(30)$ & $33(70)$ & & $55(65)$ & $30(35)$ & \\
\hline Gender & & & $0.775^{\mathrm{a}}$ & & & 0.204 \\
\hline Male & $40(24)$ & $125(76)$ & & $34(56)$ & $27(44)$ & \\
\hline Female & $5(28)$ & $13(72)$ & & $118(65)$ & $64(35)$ & \\
\hline Histology & & & $<0.001$ & & & $<0.001$ \\
\hline Adenocarcinoma & $42(32)$ & $90(68)$ & & $150(66)$ & $77(34)$ & \\
\hline Non-adenocarcinoma $^{\mathrm{b}}$ & $3(6)$ & $48(94)$ & & $2(13)$ & $14(87)$ & \\
\hline Stage & & & 0.700 & & & 0.494 \\
\hline Local and advanced & $35(24)$ & $111(76)$ & & $127(62)$ & $79(38)$ & \\
\hline Early & $10(27)$ & $27(73)$ & & $25(68)$ & $12(32)$ & \\
\hline
\end{tabular}

${ }^{a}$ Fisher's exact test. 'Includes squamous cell carcinoma, adenosquamous carcinoma and large-cell carcinoma. EGFR, epidermal growth factor receptor; $E G F R^{+}$, presence of $E G F R$ mutation; $E G F R^{-}$, absence of $E G F R$ mutation. Parenthetical data represent percentage values.

Table V. Association of clinical characteristics with the presence of EGFR mutations in patients with adenocarcinoma.

\begin{tabular}{|c|c|c|c|c|c|c|c|}
\hline \multirow[b]{2}{*}{ Characteristics } & \multirow[b]{2}{*}{$\begin{array}{c}\text { Total } \\
(\mathrm{n}=359)\end{array}$} & \multicolumn{2}{|c|}{ EGFR mutations } & \multirow{2}{*}{$\begin{array}{l}\text { Univariate } \\
\text { analysis }\end{array}$} & \multicolumn{3}{|c|}{$\begin{array}{l}\text { Multivariate } \\
\text { analysis }^{\mathrm{a}}\end{array}$} \\
\hline & & $\begin{array}{l}\text { Present } \\
(n=192)\end{array}$ & $\begin{array}{l}\text { Absent } \\
(n=167)\end{array}$ & & OR & $95 \% \mathrm{CI}$ & P-value \\
\hline Age (years) & & & & 0.439 & & & \\
\hline$\geq 60$ & $242(67)$ & $126(52)$ & $116(48)$ & & 0.92 & $0.57-1.47$ & 0.731 \\
\hline$<60$ & $117(33)$ & $66(56)$ & $51(44)$ & & Reference & & \\
\hline Gender & & & & $<0.001$ & & & \\
\hline Male & $172(48)$ & $71(41)$ & $101(59)$ & & Reference & & \\
\hline Female & $187(52)$ & $121(65)$ & $66(35)$ & & 1.19 & $0.68-2.08$ & 0.553 \\
\hline Smoking status & & & & $<0.001$ & & & \\
\hline Smokers & $132(37)$ & $42(32)$ & $90(68)$ & & Reference & & \\
\hline Non-smokers & $227(63)$ & $150(66)$ & $77(34)$ & & 3.77 & $2.10-6.77$ & $<0.001$ \\
\hline Stage & & & & 0.606 & & & \\
\hline Local and advanced & $297(83)$ & $157(53)$ & $140(47)$ & & 0.78 & $0.43-1.41$ & 0.407 \\
\hline Early & $62(17)$ & $35(56)$ & $27(44)$ & & Reference & & \\
\hline
\end{tabular}

${ }^{\text {aValid }} \mathrm{n}=359$. ${ }^{\mathrm{b}}$ Fisher's exact test. EGFR, epidermal growth factor receptor; OR, odds ratio; CI, confidence interval. Categorical parenthetical data represent percentage values.

(L858R, 52.3\%). To elucidate whether the previously described clinicopathological factors were preferentially associated with specific EGFR subtypes, we performed logistic regression analyses in patients with L858R vs. those with del 19. We observed no preferential association of del 19 or L858R with any of the clinicopathological factors using either ULR or MLR analyses (Table III).
Patient stratification by smokimg status. To elucidate the complex effects of smoking and gender in the presence of EGFR mutations, we stratified all 426 NSCLC patients into non-smokers and ever-smokers (Table IV). Although $65 \%$ of the 182 non-smoking female patients were found to harbor EGFR mutations, which was a higher incidence compared to that observed among non-smoking male patients (56\%), this 
Table VI. Association of clinical characteristics with the presence of EGFR mutations in patients with lung adenocarcinoma stratified by smoking status.

\begin{tabular}{|c|c|c|c|c|c|c|}
\hline \multirow[b]{2}{*}{ Characteristics } & \multicolumn{3}{|c|}{ Smokers $(n=132)$} & \multicolumn{3}{|c|}{ Non-smokers $(n=227)$} \\
\hline & $\begin{array}{l}E G F R^{+} \\
(\mathrm{n}=42)\end{array}$ & $\begin{array}{l}E G F R^{-} \\
(\mathrm{n}=90)\end{array}$ & P-value & $\begin{array}{c}E G F R^{+} \\
(\mathrm{n}=150)\end{array}$ & $\begin{array}{l}E G F R^{-} \\
(\mathrm{n}=77)\end{array}$ & P-value \\
\hline Age (years) & & & 0.925 & & & 0.739 \\
\hline$\geq 60$ & $30(32)$ & $65(68)$ & & $96(65)$ & $51(35)$ & \\
\hline$<60$ & $12(32)$ & $25(68)$ & & $54(68)$ & $26(33)$ & \\
\hline Gender & & & $1.000^{\mathrm{a}}$ & & & 0.377 \\
\hline Male & $38(32)$ & $80(68)$ & & $33(61)$ & $21(39)$ & \\
\hline Female & $4(29)$ & $10(71)$ & & $117(68)$ & $56(32)$ & \\
\hline Stage & & & 0.417 & & & 0.642 \\
\hline Local and advanced & $32(30)$ & $74(70)$ & & $125(65)$ & $66(35)$ & \\
\hline Early & $10(38)$ & $16(62)$ & & $25(69)$ & $11(31)$ & \\
\hline
\end{tabular}

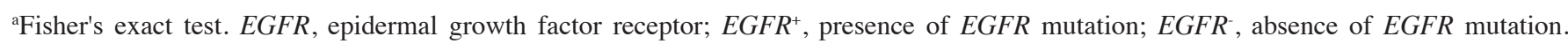
Parenthetical data represent percentage values.

Table VII. Patient populations tested and EGFR mutations precluded under different mutation testing strategies according to clinicopathological characteristics.

\begin{tabular}{|c|c|c|c|c|c|c|}
\hline \multirow[b]{2}{*}{ Population tested } & \multicolumn{2}{|c|}{$\begin{array}{l}\text { Patients } \\
\text { tested }\end{array}$} & \multicolumn{2}{|c|}{$\begin{array}{c}E G F R \text { mutations } \\
\text { detected }\end{array}$} & \multicolumn{2}{|c|}{$\begin{array}{c}E G F R \text { mutations } \\
\text { precluded }\end{array}$} \\
\hline & No. & $\%$ & No. & $\%$ & No. & $\%$ \\
\hline Adenocarcinoma only & 359 & 85 & 192 & 97.5 & 5 & 2.5 \\
\hline Non-smokers only & 243 & 57 & 152 & 77.2 & 45 & 22.8 \\
\hline Females only & 200 & 47 & 123 & 62.4 & 74 & 37.6 \\
\hline Non-smoking females & 182 & 43 & 118 & 59.9 & 79 & 40.1 \\
\hline All patients & 426 & 100 & 197 & 100 & 0 & 0 \\
\hline
\end{tabular}

EGFR, epidermal growth factor receptor.

difference was not statistically significant $(\mathrm{P}=0.204)$. Among ever-smokers, EGFR mutations were detected in $24 \%$ of male and $28 \%$ of female patients, although this difference was also not statistically significant $(\mathrm{P}=0.775)$. However, adenocarcinoma histological subtype was significantly associated with EGFR mutations in ever- and non-smokers (32 vs. $6 \%, \mathrm{P}<0.001$ and 66 vs. $13 \%, \mathrm{P}<0.001$, respectively) compared to non-adenocarcinoma NSCLC.

To confirm that gender is a confounding factor associated with EGFR mutations, we analyzed the 359 patients with lung adenocarcinoma using an MLR model and determined that smoking, but not gender, was significantly associated with EGFR mutations in patients with lung adenocarcinoma (Tables V and VI).

EGFR mutation testing. It was suggested that EGFR mutation testing is routinely performed in patients with lung adenocarcinoma in most countries (27-29). However, a number of NSCLC patients harboring EGFR mutations, who would potentially benefit from $E G F R$-TKI treatment (gefitinib or erlotinib) may be precluded if the decision to perform EGFR mutation testing is based solely on histological subtype, gender and smoking status. Our analysis demonstrated that $2.5-40.1 \%$ of NSCLC patients harboring EGFR mutations may not be identified if testing is selectively performed based upon these clinicopathological phenotypes (Table VII). In particular, if never-smoking status, female gender or never-smoking female patients with adenocarcinoma were used as the selection criteria for $E G F R$ mutation testing, 22.8, 37.6 and $40.1 \%$ of NSCLC patients with EGFR mutations, respectively, would be precluded from EGFR-TKI treatment.

\section{Discussion}

In this study, we investigated the different clinicopathological factors that are widely considered to be critically associated with EGFR mutations in NSCLC patients. We observed that, as opposed to the conclusions reported by previous studies, 
gender is not independently associated with the frequency of EGFR mutations in NSCLC patients (Tables II, V and VI) or with EGFR mutation subtypes (Table III). Furthermore, the current guidance of routine EGFR mutation analysis in NSCLC patients was validated.

Our conclusion seems to be discordant with the results of the majority of earlier studies $(5,9,12,15)$. The univariate analysis with Pearson's $\chi^{2}$ test or Fisher's exact test, or the ULR model used in the present and the majority of previous studies $(5,9,12,15)$, led to the conclusion that NSCLC patients characterized by female gender, never-smoking status and adenocarcinoma histology were more likely to harbor EGFR mutations (Table I). However, particularly in East Asian populations, the majority of female NSCLC patients have no history of smoking and their lung tumors are of the adenocarcinoma subtype, making the determination of the critical factors for EGFR mutations challenging. An MLR analysis may better elucidate the critical risk factors. In accordance with our results, supporting that gender is not associated with the frequency of EGFR mutations in NSCLC patients (Tables II and IV-VI), scattered pilot studies using MLR analyses to eliminate the confounding effects of these clinicopathological characteristics demonstrated that only adenocarcinoma and smoking history are significantly associated with EGFR mutations in NSCLC (30-32). Consistent with our findings (Tables $\mathrm{V}$ and VI), a recent study in the USA that enrolled 2,142 patients with lung adenocarcinoma revealed that the EGFR mutational frequency among female and male patients was not significantly different when patients were stratified into never- and ever-smokers (33). The results mentioned above collectively suggest that gender is not an independent factor associated with EGFR mutations in NSCLC patients.

Our findings may provide a rationale and clinical evidence to support the use of routine EGFR mutation testing prior to the administration of either EGFR-TKIs or chemotherapy as first-line treatment for lung adenocarcinoma, which is endorsed by the majority of available guidelines (27-29). Furthermore, our data demonstrated that $7 \%$ of non-adenocarcinoma NSCLC patients also harbor EGFR mutations. As shown in Table VII, up to $40.1 \%$ of NSCLC patients harboring EGFR mutations would be precluded from the significant benefit of EGFR-TKI treatment if mutational testing was restricted to female non-smokers with adenocarcinoma. Of equal importance, up to $32 \%$ of female non-smokers with adenocarcinoma (Table VII), who are commonly considered candidates for treatment with EGFR-TKIs, had no detectable EGFR mutations, indicating that first-line $E G F R$-TKI treatment would be harmful, rather than beneficial, to these patients. EGFR-TKI therapy in this population yielded meager response rates and a shorter PFS compared to those who received conventional platinum-based doublet chemotherapy (34), which may achieve a response rate of $23.5-31 \%(8,35)$.

Due to the significant differences in the percentage of EGFR mutations among East Asian and non-Asian NSCLC patients ( $\sim 30$ vs. $8 \%$, respectively), ethnicity is considered to be significantly associated with EGFR mutation status $(9,18)$. However, this observation may be confounded by clinicopathological parameters, such as histological subtype and smoking behavior. Our analysis (Table VIII) suggested that smoking
Table VIII. Comparison of the presence of EGFR mutations in patients with adenocarcinoma stratified by smoking status.

\begin{tabular}{lccccc}
\hline & \multicolumn{2}{c}{ Ever-smokers } & & \multicolumn{2}{c}{ Non-smokers } \\
\cline { 2 - 3 } \cline { 5 - 6 } Study group & $\begin{array}{c}E G F R^{+} \\
(\%)\end{array}$ & $\begin{array}{c}E G F R^{-} \\
(\%)\end{array}$ & & $\begin{array}{c}E G F R^{+} \\
(\%)\end{array}$ & $\begin{array}{c}E G F R^{-} \\
(\%)\end{array}$ \\
\hline $\begin{array}{l}\text { Current study } \\
(\mathrm{n}=359)\end{array}$ & 31 & 69 & & 66 & 34 \\
$\begin{array}{l}\text { USA study } \\
(\mathrm{n}=2,142)^{\mathrm{a}}\end{array}$ & 13 & 87 & 52 & 48
\end{tabular}

${ }^{\text {aD }}$ Data were derived from reference no. 33 with the permission of the American Society of Clinical Oncology. EGFR, epidermal growth factor receptor; $E G F R^{+}$, presence of $E G F R$ mutation; $E G F R^{-}$, absence of $E G F R$ mutation; USA, United States of America.

status, but not ethnicity, is the major determinant for $E G F R$ mutations in lung cancer among different populations. Additionally, the contribution from the cumulative smoking dose to the EGFR mutation frequency should also be considered. Recent studies demonstrated that the cumulative smoking dose is inversely correlated with the presence of EGFR mutations in lung adenocarcinoma $(32,33)$, ranging from 4 to $34 \%$ in smokers with various numbers of smoking pack years (33). Therefore, the difference in the percentage of EGFR mutations among smokers (Table VI) may be attributed to the cumulative smoking dose.

Another factor that may contribute to the differences in the incidence of EGFR mutations in never-smokers among different ethnic groups may be cumulative exposure to environmental tobacco smoke (ETS). Recently, household and workplace ETS, in particular, were reported to be inversely associated with the frequency of EGFR mutations in non-smokers with NSCLC (36). Specifically, the presence of EGFR mutations in lung adenocarcinoma was significantly different in never-smokers with and without ETS exposure (40.5 and $64.1 \%$, respectively; $\mathrm{P}=0.015$ ). Therefore, the difference in the percentage of EGFR mutations in either never- or ever-smokers among the two study groups (Table VIII) may correlate with the cumulative effect of direct or indirect exposure to smoking, suggesting that ethnicity may not be a crucial factor associated with EGFR mutations in NSCLC patients.

However, there were several limitations to this study. One limitation was the relatively small sample size, particularly the number of female smokers, which may affect our analyses. Since $<10 \%$ of women are smokers and only $6.4 \%$ of female lung cancer patients are smokers in Taiwan (6), it is difficult to recruit an adequate number of female smokers in lung cancer studies. Furthermore, we were unable to present a comprehensive image on the EGFR mutation status of all the NSCLC patients, since not every patient had adequate tissue for mutation testing. Therefore, our findings require validation by further large-scale studies. The elucidation of the association between these factors and EGFR mutations may help identify factors that increase lung cancer susceptibility in the never-smoking population and design optimal preventive strategies. 
In conclusion, this study demonstrated that gender is a confounding factor, whereas histological subtype and smoking status are independently and significantly associated with EGFR mutations in NSCLC patients. These findings support the current guidance that EGFR mutation testing should be routinely performed in patients with lung cancer of the adenocarcinoma subtype, regardless of their gender, and may indicate that gender may not be associated with tumorigenesis in NSCLC patients harboring EGFR mutations.

\section{Acknowledgements}

The authors would like to thank the Taipei Medical University and Hospital, the Center of Excellence for Clinical Trial and Research in Neuroscience, the Institute of Biomedical Sciences, Academia Sinica, National Yang-Ming University and the National Science Council, Executive Yuan, Taiwan, R.O.C. for their support.

\section{References}

1. Badar F, Meerza F, Khokhar RA, et al: Characteristics of lung cancer patients - the Shaukat Khanum Memorial experience. Asian Pac J Cancer Prev: 245-248, 2006.

2. Khuder SA: Effect of cigarette smoking on major histological types of lung cancer: a meta-analysis. Lung Cancer 31: 139-148, 2001.

3. Gabrielson E: Worldwide trends in lung cancer pathology. Respirology 11: 533-538, 2006

4. Parkin DM, Bray F, Ferlay J and Pisani P: Global cancer statistics, 2002. CA Cancer J Clin 55: 74-108, 2005.

5. Toh CK, Gao F, Lim WT, et al: Never-smokers with lung cancer: epidemiologic evidence of a distinct disease entity. J Clin Onco 24: 2245-2251, 2006.

6. Hsu LH, Chu NM, Liu CC, Tsai SY, You DL, Ko JS, Lu MC and Feng AC: Sex-associated differences in non-small cell lung cancer in the new era: is gender an independent prognostic factor? Lung Cancer 66: 262-267, 2009.

7. Kawaguchi T, Takada M, Kubo A, et al: Gender, histology, and time of diagnosis are important factors for prognosis: analysis of 1,499 never-smokers with advanced non-small cell lung cancer in Japan. J Thorac Oncol 5: 1011-1017, 2010.

8. Ding L, Getz G, Wheeler DA, et al: Somatic mutations affect key pathways in lung adenocarcinoma. Nature 455: 1069-1075, 2008

9. Shigematsu H and Gazdar AF: Somatic mutations of epidermal growth factor receptor signaling pathway in lung cancers. Int J Cancer 118: 257-262, 2006.

10. Sanders HR and Albitar M: Somatic mutations of signaling genes in non-small-cell lung cancer. Cancer Genet Cytogenet 203: 7-15, 2010.

11. Subramanian J and Govindan R: Molecular genetics of lung cancer in people who have never smoked. Lancet Oncol 9: 676-682, 2008.

12. Sequist LV, Heist RS, Shaw AT, et al: Implementing multiplexed genotyping of non-small-cell lung cancers into routine clinical practice. Ann Oncol 22: 2616-2624, 2011.

13. Mok TS, Wu YL, Thongprasert S, et al: Gefitinib or carboplatinpaclitaxel in pulmonary adenocarcinoma. N Engl J Med 361: 947-957, 2009.

14. Rosell R, Moran T, Queralt C, et al: Screening for epidermal growth factor receptor mutations in lung cancer. $\mathrm{N}$ Engl $\mathrm{J}$ Med 361: 958-967, 2009.

15. Maemondo M, Inoue A, Kobayashi K, et al: Gefitinib or chemotherapy for non-small-cell lung cancer with mutated EGFR. N Engl J Med 362: 2380-2388, 2010.

16. Zhou C, Wu YL, Chen G, et al: Erlotinib versus chemotherapy as first-line treatment for patients with advanced EGFR mutation-positive non-small-cell lung cancer (OPTIMAL, CTONG-0802): a multicentre, open-label, randomised, phase 3 study. Lancet Oncol 12: 735-742, 2011.

17. Rosell R, Carcereny E, Gervais R, et al: Erlotinib versus standard chemotherapy as first-line treatment for European patients with advanced EGFR mutation-positive non-small-cell lung cancer (EURTAC): a multicentre, open-label, randomised phase 3 trial. Lancet Oncol 13: 239-246, 2012.
18. Shigematsu H, Lin L, Takahashi T, et al: Clinical and biological features associated with epidermal growth factor receptor gene mutations in lung cancers. J Natl Cancer Inst 97: 339-346, 2005.

19. Sugio K, Uramoto H, Ono K, Oyama T, Hanagiri T, Sugaya M, Ichiki Y, So T, Nakata S, Morita M and Yasumoto K: Mutations within the tyrosine kinase domain of EGFR gene specifically occur in lung adenocarcinoma patients with a low exposure of tobacco smoking. Br J Cancer 94: 896-903, 2006.

20. Boldrini L, Ali G, Gisfredi S, et al: Epidermal growth factor receptor and K-RAS mutations in 411 lung adenocarcinomas: A population-based prospective study. Oncol Rep 22: 683-691, 2009.

21. Toyooka S, Matsuo K, Shigematsu H, et al: The impact of sex and smoking status on the mutational spectrum of epidermal growth factor receptor gene in non small cell lung cancer. Clin Cancer Res 13: 5763-5768, 2007.

22. Harichand-Herdt S and Ramalingam SS: Gender-associated differences in lung cancer: clinical characteristics and treatment outcomes in women. Semin Oncol 36: 572-580, 2009.

23. Fan WC, Yu CJ, Tsai CM, et al: Different efficacies of erlotinib and gefitinib in Taiwanese patients with advanced non-small cell lung cancer: a retrospective multicenter study. J Thorac Oncol 6: 148-155, 2011.

24. Shukuya T, Takahashi T, Kaira R, et al: Efficacy of gefitinib for non-adenocarcinoma non-small-cell lung cancer patients harboring epidermal growth factor receptor mutations: a pooled analysis of published reports. Cancer Sci 102: 1032-1037, 2011.

25. Pao W and Ladanyi M: Epidermal growth factor receptor mutation testing in lung cancer: searching for the ideal method. Clin Cancer Res 13: 4954-4955, 2007.

26. Lee CN, Yu MC, Bai KJ, Chang JH, Fang CL, Hsu HL, Huang BS, Lu PC and Liu HE: NAT2 fast acetylator genotypes are associated with an increased risk for lung cancer with wildtype epidermal growth factor receptors in Taiwan. Lung Cancer 64: 9-12, 2009.

27. Salto-Tellez M, Tsao MS, Shih JY, et al: Clinical and testing protocols for the analysis of epidermal growth factor receptor mutations in East Asian patients with non-small cell lung cancer: a combined clinical-molecular pathological approach. J Thorac Oncol 6: 1663-1669, 2011.

28. Pirker R, Herth FJ, Kerr KM, et al: Consensus for EGFR mutation testing in non-small cell lung cancer: results from a European workshop. J Thorac Oncol 5: 1706-1713, 2010.

29. Beasley MB and Milton DT: ASCO provisional clinical opinion: epidermal growth factor receptor mutation testing in practice. J Oncol Pract 7: 202-204, 2011.

30. Tokumo M, Toyooka S, Kiura K, et al: The relationship between epidermal growth factor receptor mutations and clinicopathologic features in non-small cell lung cancers. Clin Cancer Res 11: 1167-1173, 2005.

31. Tanaka T, Matsuoka M, Sutani A, et al: Frequency of and variables associated with the EGFR mutation and its subtypes. Int J Cancer 126: 651-655, 2010.

32. Lee YJ, Shim HS, Kang YA, Hong SJ, Kim HK, Kim H, Kim SK, Choi SH, Kim JH and Cho BC: Dose effect of cigarette smoking on frequency and spectrum of epidermal growth factor receptor gene mutations in Korean patients with non-small cell lung cancer. J Cancer Res Clin Oncol 136: 1937-1944, 2010.

33. D'Angelo SP, Pietanza MC, Johnson ML, Riely GJ, Miller VA, Sima CS, Zakowski MF, Rusch VW, Ladanyi M and Kris MG: Incidence of EGFR exon 19 deletions and L858R in tumor specimens from men and cigarette smokers with lung adenocarcinomas. J Clin Oncol 29: 2066-2070, 2011.

34. Fukuoka M, Wu YL, Thongprasert S, et al: Biomarker analyses and final overall survival results from a phase III, randomized, open-label, first-line study of gefitinib versus carboplatin/ paclitaxel in clinically selected patients with advanced nonsmall-cell lung cancer in Asia (IPASS). J Clin Oncol 29: 2866-2874, 2011.

35. Jänne PA, Wang X, Socinski MA, Crawford J, Stinchcombe TE, Gu L, Capelletti M, Edelman MJ, Villalona-Calero MA, Kratzke R, Vokes EE and Miller VA: Randomized phase II trial of erlotinib alone or with carboplatin and paclitaxel in patients who were never or light former smokers with advanced lung adenocarcinoma: CALGB 30406 trial. J Clin Oncol 30: 2063-2069, 2012

36. Lee YJ, Cho BC, Jee SH, Moon JW, Kim SK, Chang J, Chung KY, Park IK, Choi SH and Kim JH: Impact of environmental tobacco smoke on the incidence of mutations in epidermal growth factor receptor gene in never-smoker patients with non-small-cell lung cancer. J Clin Oncol 28: 487-492, 2010. 